\title{
Diminution of factual power loss by enhanced bacterial foraging optimization algorithm
}

\author{
Kanagasabai Lenin \\ Department of Electrical and Electronics Engineering, Prasad V. Potluri Siddhartha Institute of Technology, India
}

\begin{tabular}{l} 
Article Info \\
\hline Article history: \\
Received Jan 3, 2020 \\
Revised Feb 19, 2020 \\
Accepted Mar 3, 2020 \\
\hline
\end{tabular}

\section{Keywords:}

Enhanced bacterial foraging optimization

Optimal reactive power

Transmission loss

\begin{abstract}
This paper presents an enhanced bacterial foraging optimization (EBFO) algorithm for solving the optimal reactive power problem. Bacterial foraging optimization is based on foraging behaviour of Escherichia coli bacteria which present in the human intestine. Bacteria have inclination to congregate the nutrient-rich areas by an action called as Chemo taxis. The bacterial foraging process consists of four chronological methods i.e. chemo taxis, swarming and reproduction and elimination-dispersal. In this work rotation angle adaptively and incessantly modernized, which augment the diversity of the population and progress the global search capability. The quantum rotation gate is utilized for chemo taxis to modernize the state of chromosome projected EBFO algorithm has been tested in standard IEEE 14,300 bus test system and simulation results show the projected algorithm reduced the real power loss extensively.
\end{abstract}

This is an open access article under the CC BY-SA license.

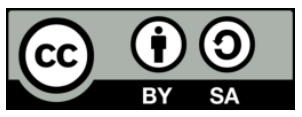

Corresponding Author:

Kanagasabai Lenin,

Department of Electrical and Electronics Engineering,

Prasad V. Potluri Siddhartha Institute of Technology,

Kanuru, Vijayawada, Andhra Pradesh-520007, India.

Email: gklenin@gmail.com

\section{INTRODUCTION}

Reactive power problem plays a key role in secure and economic operations of power system. Optimal reactive power problem has been solved by variety of types of methods [1-6]. Nevertheless numerous scientific difficulties are found while solving problem due to an assortment of constraints. Evolutionary techniques [7-16] are applied to solve the reactive power problem, but the main problem is many algorithms get stuck in local optimal solution and failed to balance the exploration and exploitation during the search of global solution. This research work presents an enhanced bacterial foraging optimization (EBFO) algorithm for solving the optimal reactive power problem. It is a new-fangled hybrid optimization algorithm, which merge the quantum based evolutionary algorithm with the bacterial foraging algorithm. Quantum rotation angle is set through the look-up table procedure, and rotation angle is acquired is discrete but cannot completely replicate the fundamental situation of the solution space. In this work rotation angle adaptively and incessantly modernized, which augment the diversity of the population and progress the global search capability. Projected enhanced bacterial foraging optimization (EBFO) algorithm has been tested in standard IEEE 14,300 bus test system and simulation results show the projected algorithm reduced the real power loss extensively.

\section{PROBLEM FORMULATION}

Objective of the problem is to reduce the true power loss: 


$$
\mathrm{F}=\mathrm{P}_{\mathrm{L}}=\sum_{\mathrm{k} \in \mathrm{Nbr}} \mathrm{g}_{\mathrm{k}}\left(\mathrm{V}_{\mathrm{i}}^{2}+\mathrm{V}_{\mathrm{j}}^{2}-2 \mathrm{~V}_{\mathrm{i}} \mathrm{V}_{\mathrm{j}} \cos \theta_{\mathrm{ij}}\right)
$$

Voltage deviation given as follows:

$$
\mathrm{F}=\mathrm{P}_{\mathrm{L}}+\omega_{\mathrm{v}} \times \text { Voltage Deviation }
$$

Voltage deviation given by:

$$
\text { Voltage Deviation }=\sum_{\mathrm{i}=1}^{\mathrm{Npq}}\left|\mathrm{V}_{\mathrm{i}}-1\right|
$$

Constraint (Equality);

$$
P_{G}=P_{D}+P_{L}
$$

Constraints (Inequality);

$$
\begin{aligned}
& \mathrm{P}_{\mathrm{gslack}}^{\min } \leq \mathrm{P}_{\text {gslack }} \leq \mathrm{P}_{\text {gslack }}^{\max } \\
& \mathrm{Q}_{\mathrm{gi}}^{\min } \leq \mathrm{Q}_{\mathrm{gi}} \leq \mathrm{Q}_{\mathrm{gi}}^{\max }, \mathrm{i} \in \mathrm{N}_{\mathrm{g}} \\
& \mathrm{V}_{\mathrm{i}}^{\min } \leq \mathrm{V}_{\mathrm{i}} \leq \mathrm{V}_{\mathrm{i}}^{\max }, \mathrm{i} \in \mathrm{N} \\
& \mathrm{T}_{\mathrm{i}}^{\min } \leq \mathrm{T}_{\mathrm{i}} \leq \mathrm{T}_{\mathrm{i}}^{\max }, \mathrm{i} \in \mathrm{N}_{\mathrm{T}} \\
& \mathrm{Q}_{\mathrm{c}}^{\min } \leq \mathrm{Q}_{\mathrm{c}} \leq \mathrm{Q}_{\mathrm{C}}^{\max }, \mathrm{i} \in \mathrm{N}_{\mathrm{C}}
\end{aligned}
$$

\section{ENHANCED BACTERIAL FORAGING OPTIMIZATION ALGORITHM}

Enhanced bacterial foraging optimization algorithm is a new-fangled hybrid optimization algorithm, which merge the quantum based evolutionary algorithm with the bacterial foraging algorithm. Quantum rotation angle is set through the look-up table procedure, and rotation angle is acquired is discrete but cannot completely replicate the fundamental situation of the solution space [17].

- Quantum bit

In conventional bit have two values 0 or 1 , but the superposition the values will be in qubit. With bracket data the state of a qubit can be symbolized by:

$$
|\varphi\rangle=\alpha|0\rangle+\beta|1\rangle
$$

where $|\varphi\rangle$ symbolize vector space. Classical bit values 0 and 1 can be represented by $|0\rangle$ and $|1\rangle$; $\mathrm{c}$ and $\mathrm{d}$ is complex numbers such that:

$$
|c|^{2}+|d|^{2}=1
$$

$\mathrm{c}$ and $\mathrm{d}$ symbolize the complex number of the probability amplitudes.

- Quantum revolution gate

Quantum rotation gate is frequently used and defined by:

$$
U(\theta)=\left(\begin{array}{cc}
\cos \theta-\sin \theta \\
\sin \theta & \cos \theta
\end{array}\right)
$$

Single quantum chromosome is indicated by $q_{j}^{t}$,

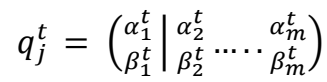

" $m$ " denotes the number of quantum bits; $j=1,2, \ldots, n$, size of population symbolized by $n$; and genetic algebra indicated by t. $\left(\alpha_{i}^{t}, \beta_{i}^{t}\right)$, are initialize with $(1 / \sqrt{2}, 1 / \sqrt{2})$ and it designate single quantum bit chromosome which symbolize the linear superposition with the similar possibility in all probable states. 


$$
\left|\emptyset_{q_{j}^{t}}\right\rangle=\sum_{k=1}^{2^{m}} \frac{1}{\sqrt{2^{m}}}\left|s_{k}\right\rangle
$$

where $\mathrm{S}_{\mathrm{k}}$ is the number of $\mathrm{k}$ state of chromosome \& it symbolized by the binary string $\left(x_{1}, x_{2}, \ldots, x_{m}\right)$, $x_{i}(1,2, \ldots, m)$ will be 0 or 1 . When $(\mathrm{t})=\left\{\mathrm{P}_{1}^{\mathrm{t}}, \mathrm{P}_{2}^{\mathrm{t}}, \ldots . \mathrm{P}_{\mathrm{n}}^{\mathrm{t}}\right\}$, a group of binary population attained. $P_{i}^{t}(1,2, \ldots, n)$ is a binary string of the length $m$ and is created by possibility of quantum, with picking every bit using $\left|\alpha_{i}^{t}\right|^{2}$ or $\left|\beta_{i}^{t}\right|^{2}$ of $q_{j}^{t} \cdot P_{i}^{t}(1,2, \ldots, n)$ is evaluate the fitness value.

Bacterial foraging optimization is based on foraging behaviour of Escherichia coli bacteria which present in the human intestine. Bacteria have inclination to congregate the nutrient-rich areas by an action called as chemo taxis. The bacterial foraging process consists of four chronological methods i.e. chemo taxis, swarming and reproduction and elimination-dispersal. Chemo taxis: -In the computational chemo taxis, the progression of $\mathrm{i}^{\text {th }}$ bacterium subsequent to one step can be symbolized as:

$$
\theta^{i}(j+1, k, l)=\theta^{i}(j, k, l)+C(i) \varphi(j)
$$

Swarming: -Cell to Cell indication in E. coli swarm is scientifically symbolized as:

$$
\begin{aligned}
& j_{c c}(\theta, P(j, k, l))=\sum_{i=1}^{S} j_{c c}\left(\theta, \theta^{i}(j, k, l)\right)= \\
& \sum_{i=1}^{s}\left[-d_{\text {attractant }} \exp \left(-\delta_{\text {attractant }} \sum_{m=1}^{p}\left(\theta_{m}-\right.\right.\right. \\
& \left.\left.\left.\theta_{m}^{i}\right)^{2}\right)\right]+\sum_{i=1}^{s}\left[h_{\text {repellent }} \exp \left(-\delta_{\text {repellent }} \sum_{m=1}^{p}\left(\theta_{m}-\theta_{m}^{i}\right)^{2}\right)\right]
\end{aligned}
$$

Reproduction: subsequent to the conclusion of all $\mathrm{N}_{\mathrm{c}}$ chemo tactic stage, reproduction action will begin. In ascending order fitness value of the bacteria will be stored. Elimination and dispersal: it is necessary to spread the bacteria may be steadily or abruptly hence opportunity of being ensnared in to local minima will be eliminated. Dispersion operation takes place after a definite number of reproduction procedures. In the period of the chemo taxis loop topple direction is modernized by:

$$
\begin{aligned}
& \varphi(j+1)=\omega * \varphi(j)+C_{1} * \text { rand } *(\text { pbest }- \text { pcurrent })+c_{2} * \text { rand } * \\
& (\text { gbest }- \text { pcurrent })
\end{aligned}
$$

The customized operator of probability amplitude is defined as:

$$
\left[\begin{array}{l}
\alpha_{i}^{*} \\
\beta_{i}^{*}
\end{array}\right]=\left\{\begin{array}{l}
(\sqrt{\gamma}, \sqrt{1-\gamma})^{T},\left|\alpha_{i}^{*}\right|^{2} \leq \gamma \\
(\sqrt{1-\gamma}, \sqrt{\gamma}),\left|\alpha_{i}^{*}\right|^{2} \geq \gamma \\
\left(\alpha_{i}^{*}, \beta_{i}^{*}\right)^{T} \quad \text { else }
\end{array}\right.
$$

Enhanced quantum rotation angle is done by:

$$
\begin{aligned}
& M_{1}=\operatorname{sign}\left(\left(x_{i}-0.5\right) \alpha_{i} \beta_{i}\right) \\
& M_{2}=\operatorname{sign}\left(\theta_{i}-\theta_{b}\right) \\
& \theta=M_{1} M_{2} \theta_{0} e^{(-\eta)}
\end{aligned}
$$

Direction of the rotation angle is controlled by $M_{1}$ and $M_{2}$ and size of the rotation angle is controlled by $\eta, \theta 0$. Present fitness value of chemo tactic step size varying is likely to endow with improved convergence performance. Adaption scheme for the step size for $\mathrm{i}_{\mathrm{th}}$ bacterium is given by:

$$
C(i)=\frac{\left|j^{i}(\theta)\right|}{\left|j^{i}(\theta)+\Psi\right|}=\frac{1}{1+\frac{\Psi}{j^{i}(\theta)}}
$$

Where $\Psi$ is positive constant.

$j^{i} \theta=$ Cost function of the $i_{\text {th }}$ bacterium

$\mathrm{C}(\mathrm{i}) \quad=$ Variable run (step) length of $\mathrm{i}_{\mathrm{th}}$ bacterium

Step a : Initialize the parameters

Step $b \quad$ : Procedure of elimination and dispersal loop

Step c : Begin of reproduction loop

Step d : Begin of chemo taxis loop 
Step e : When $\mathrm{j}<\mathrm{Nc}$, then go to Step $\mathrm{d}$ chemo taxis will be continued because bacteria life is not over.

Step f : Reproduction procedure applied

Step g : When $\mathrm{k}<\mathrm{N}_{\mathrm{re}}$, then go to Step c; when specific number of reproduction steps are not reached, then commence the subsequent generation of the chemo tactic loop.

Step $\mathrm{h}$ : Elimination-dispersal: For $\mathrm{i}=1,2, . ., \mathrm{S}$ with the probability $\mathrm{p}_{\mathrm{ed}}$, each bacterium are eliminated and disperse, then number of bacteria in the population will be constant. For above action, when a bacterium is eradicated, merely disperse one to an arbitrary location in the domain. When $1<\mathrm{N}_{\mathrm{ed}}$ then go to Step b, or else end;

Step $\mathrm{i}$ : When the end condition of the projected algorithm is fulfilled, then the optimal fitness value and the consequent individual position rank are the output, or else return to Step c.

\section{SIMULATION RESULTS}

At first in standard IEEE 14 bus system the validity of the proposed EBFO algorithm has been tested and comparison results are presented in Table 1. Then IEEE 300 bus system [18] is used as test system to validate the performance of the EBFO algorithm. Table 2 shows the comparison of real power loss obtained after optimization.

Table 1. Comparison of results

\begin{tabular}{cccc}
\hline Control variables & ABCO [19] & IABCO [19] & EBFO \\
\hline V1 & 1.06 & 1.05 & 1.03 \\
V2 & 1.03 & 1.05 & 1.00 \\
V3 & 0.98 & 1.03 & 1.00 \\
V6 & 1.05 & 1.05 & 1.00 \\
V8 & 1.00 & 1.04 & 0.90 \\
Q9 & 0.139 & 0.132 & 0.100 \\
T56 & 0.979 & 0.960 & 0.900 \\
T47 & 0.950 & 0.950 & 0.900 \\
T49 & 1.014 & 1.007 & 1.000 \\
Ploss (MW) & 5.92892 & 5.50031 & 4.1648 \\
\hline
\end{tabular}

Table 2. Comparison of real power loss

\begin{tabular}{ccccc}
\hline Parameter & Method EGA [20] & Method EEA [20] & Method CSA [21] & EBFO \\
\hline PLOSS (MW) & 646.2998 & 650.6027 & 635.8942 & 618.0482 \\
\hline
\end{tabular}

\section{CONCLUSION}

In this work EBFO algorithm has been successfully solved the optimal reactive power problem. Rotation angle adaptively and incessantly modernized which augmented the diversity of the population and progress the global search capability. The quantum rotation gate is utilized for chemo taxis to modernize the state of chromosome projected EBFO algorithm has been tested in standard IEEE 14,300 bus test system and simulation results show the projected algorithm reduced the real power loss extensively.

\section{REFERENCES}

[1] K. Y. Lee, Y. M. Park, and J. L. Ortiz, "Fuel-cost minimisation for both real-and reactive-power dispatches," in IEE Proceedings C-Generation, Transmission and Distribution, vol. 131, no. 3, pp. 85-93, May 1984.

[2] N. I. Deeb and S. M. Shahidehpour, "An efficient technique for reactive power dispatch using a revised linear programming approach," Electric Power System Research, vol. 15, no. 2, pp. 121-134, October 1988.

[3] M. Bjelogrlic, M. S. Calovic, P. Ristanovic, and B. S. Babic, "Application of Newton's optimal power flow in voltage/reactive power control," in IEEE Transactions on Power Systems, vol. 5, no. 4, pp. 1447-1454, Nov. 1990.

[4] S. Granville, "Optimal reactive dispatch through interior point methods," in IEEE Transactions on Power Systems, vol. 9, no. 1, pp. 136-146, Feb. 1994.

[5] N. Grudinin, "Reactive power optimization using successive quadratic programming method," in IEEE Transactions on Power Systems, vol. 13, no. 4, pp. 1219-1225, Nov. 1998.

[6] Wei Yan, Juan Yu, D. C. Yu, and K. Bhattarai, "A new optimal reactive power flow model in rectangular form and its solution by predictor corrector primal dual interior point method," in IEEE Transactions on Power Systems, vol. 21, no. 1, pp. 61-67, Feb. 2006.

[7] A. Mukherjee and V. Mukherjee, "Solution of optimal reactive power dispatch by chaotic krill herd algorithm," in IET Generation, Transmission \& Distribution, vol. 9, no. 15, pp. 2351-2362, 19112015.

[8] Zechun Hu, Xifan Wang, and Gareth Taylor, "Stochastic optimal reactive power dispatch: Formulation and solution method," International Journal of Electrical Power \& Energy Systems, vol. 32, no. 6, pp. 615-621, July 2010. 
[9] Mahaletchumi A/P Morgan, Nor Rul Hasma Abdullah, Mohd Herwan Sulaiman, Mahfuzah Mustafa, and Rosdiyana Samad, "Multi-objective evolutionary programming (MOEP) using mutation based on adaptive mutation operator (AMO) applied for optimal reactive power dispatch," ARPN Journal of Engineering and Applied Sciences, vol. 11, no. 14, pp. 8884-8888, 2016.

[10] K. Pandiarajan and C. K. Babulal, "Fuzzy harmony search algorithm based optimal power flow for power system security enhancement," International Journal of Electrical Power \& Energy Systems, vol. 78, pp. 72-79, June 2016.

[11] Morgan Mahaletchumi, Abdullah Nor Rul Hasma, H. Sulaiman M., Mustafa Mahfuzah, and Samad Rosdiyana, "Benchmark studies on optimal reactive power dispatch (ORPD) based multi-objective evolutionary programming (MOEP) using mutation based on adaptive mutation adapter (AMO) and polynomial mutation operator (PMO)," Journal of Electrical Systems, vol. 12, no. 1, 121-132, 2016.

[12] Rebecca Ng Shin Mei, Mohd Herwan Sulaiman, and Zuriani Mustaffa, "Ant lion optimizer for optimal reactive power dispatch solution," J. Electrical Systems Special Issue AMPE2015, pp. 68-74, 2016.

[13] Antonio Gagliano and Francesco Nocera, "Analysis of the performances of electric energy storage in residential applications," International Journal of Heat and Technology, vol. 35, Special Issue 1, pp. S41-S48, September 2017.

[14] M. Caldera, P. Ungaro, G. Cammarata, and G. Puglisi, "Survey-based analysis of the electrical energy demand in Italian households," Mathematical Modelling of Engineering Problems, vol. 5, no. 3, pp. 217-224, September 2018.

[15] Amilkar Puris, Rafael Bello, Daniel Molina, and Francisco Herrera, "Variable mesh optimization for continuous optimization problems," Soft Computing, vol. 16, no. 3, pp. 511-525, March 2012.

[16] Kenneth V. Price, Rainer M. Storn, and Jouni A. Lampinen, "Differential evolution: A practical approach to global optimization," Berlin, Germany: Springer, 2006.

[17] H. Gao and C. Li, "Quantum-inspired bacterial foraging algorithm for parameter adjustment in green cognitive radio," in Journal of Systems Engineering and Electronics, vol. 26, no. 5, pp. 897-907, 2015.

[18] R. C. August, "Power system test case archive: 300 bus power flow test case," 1993. [Online]. Available at: https://labs.ece.uw.edu/pstca/pf300/pg_tca300bus.htm.

[19] C. M. K. Sivalingam, S. Ramachandran, and P. S. S. Rajamani, "Reactive power optimization in a power system network through metaheuristic Algorithms, Turkish Journal of Electrical Engineering \& Computer Sciences, vol. 25, no. 6, pp. 4615-4623, 2017.

[20] S. Surender Reddy, P. R. Bijwe, and A. R. Abhyankar, "Faster evolutionary algorithm based optimal power flow using incremental variables," International Journal of Electrical Power \& Energy Systems, vol. 54, pp. 198-210, January 2014.

[21] S. Surender Reddy, "Optimal reactive power scheduling using cuckoo search algorithm," International Journal of Electrical and Computer Engineering, vol. 7, no. 5, pp. 2349-2356, October 2017. 